\title{
A STUDY TO ASSESS THE KNOWLEDGE REGARDING PREVENTION OF CHILDHOOD OBESITY AMONG MOTHERS OF CHILDREN (0-12 YRS) IN KIRUMAMPAKKAM, VILLAGE, PUDUCHERRY.
}

Mrs. S. Lavanya

\begin{abstract}
Obesity is increasing at an alarming rate throughout the world. Today it is estimated that there are more than 300 million obese people world-wide. Obesity is a condition of excess today fat often associated with a large number of debilitating and life threatening disorders. The objectives of the study was to assess the level of knowledge regarding prevention of childhood obesity among the mother to associate the level of knowledge with selected demographic variables. Descriptive research design was used for the study. The study was conducted among mothers of children between the age group of 0-12 years in Kirumampakkam Village, Puducherry. 30 mothers were selected based on the convenient sampling technique. The data was collected from the mother who have children between the age group of 0-12 years. The result showed that out of 30 samples 14(46.6\%) mothers had inadequate knowledge, 13 (43.3\%) mother had moderately adequate knowledge and 3 (10\%) of mothers had well adequate knowledge. The study revealed that the majority of the mothers has inadequate and moderately adequate knowledge. So, the mothers need education regarding the prevention of childhood obesity.
\end{abstract}

\section{Key words: Knowledge, Prevention\& Childhood Obesity}

\section{Introduction}

Chubby babies and toddlers were more likely to get infections and contagious diseases. Over the past three decades, the number of children considered overweight or obese has double from $15 \%$ in the 1970 's to $30 \%$ today. Childhood obesity rates have tripled in the past 30 years. Now as many as $17 \%$ of US adolescents and $16 \%$ of US children are affected.
Today being overweight puts a child at risk for developing chronic diseases, joint diseases and severely limits physical activities. Childhood obesity has physical psychological implications. In India, childhood obesity is increasing rapidly due to modernization of life style and food habits. There are many factors contributing to childhood obesity. It is very important to identify such factors and also the children 
prone to be obese. Education of the mother about prevention of childhood is important responsibilities of the health care workers.

\section{Statement of the problem}

A study to assess the knowledge regarding prevention of childhood obesity among mothers of children (0-12 yrs) in Kirumampakkam Village, Puducherry.

\section{Objectives}

- To assess the level of knowledge regarding prevention of childhood obesity among the mothers.

- To associate the level of knowledge with selected demographic variables.

\section{Research Methodology}

Research Approach : Quantitative Research was used to assess the knowledge regarding prevention of childhood obesity.

Research Design Descriptive research design was chosen for the study to assess the level of knowledge of mother regarding childhood obesity.

Setting of the study The study was conducted at Kirumampakkam Village, Puducherry.

Population of the Study : The study population includes the mother between the age group of 21-40 years and their children from 0-12 years and who are residing in Kirumampakkam Village, Puducherry.

\section{Sample Size}

The sample size of the study consists of 30 mothers who are having the children between the age group $0-12$ years.

\section{Sampling technique}

The mother were selected through non probability convenient criteria were selected as samples.

\section{Criteria for sample selection}

\section{Inclusion Criteria}

- Mothers of age group from 21-40 years and their children from $0-12$ years of age.

- Mothers available during data collection period.

- Mothers who understand Tamil or English

- Exclusion Criteria

- Mothers of adolescents.

\section{Data collection Procedure}

The data were collected after obtaining the formal permission from the village leader and the study participants. After explaining the purpose of the study, the structured questionanaire was provided to the samples and the time limit of 30 minutes was given for the completion of questionnaire. The doubts raised from the samples were clarified by the investigator. 
knowledge and $3(10 \%)$ of mothers had

Table 1

Frequency and Percentage distribution of Knowledge among Mothers Regarding Prevention of Childhood Obesity

\begin{tabular}{|l|l|l|l|}
\hline $\begin{array}{l}\text { Sl. } \\
\text { No. }\end{array}$ & $\begin{array}{l}\text { Level of } \\
\text { Knowledge }\end{array}$ & Frequency & Percentage \\
\hline 1. & $\begin{array}{l}\text { Inadequate } \\
\text { Knowledge }\end{array}$ & 14 & $46.6 \%$ \\
\hline 2. & $\begin{array}{l}\text { Moderately } \\
\text { Adequate } \\
\text { Knowledge }\end{array}$ & 13 & $43.4 \%$ \\
\hline 3. & $\begin{array}{l}\text { Adequate } \\
\text { Knowledge }\end{array}$ & 3 & $10 \%$ \\
\hline
\end{tabular}

\section{Major Findings}

Wit regard to age of mother 13 $(43.5 \%)$ were in the age group of $21-25$ years, majority of mothers had secondary education, among 30 mothers 25 (84\%) were housewives, 16 (54\%) were living in joint family, and 21 (70\%) had one child, $30(100 \%)$ mothers come under non vegetarian group, majority of the child 17 $(56 \%)$ were male baby.

With regard to the mother knowledge on regarding prevention of childhood obesity, out of 30 samples 14 (46.6\%) mothers had inadequate knowledge, 13 (43.3\%) mothers had moderately adequate adequate knowledge.

The association of the level of knowledge among mothers on prevention of childhood obesity with selected demographic variables revealed that the occupation, income, number of children in the family and educational qualification of mothers were significant at the level of $\mathrm{P}<0.05$.

\section{Discussion}

Childhood obesity is one of the leading health problem in both developed and developing countries. The present study was conducted to assess the knowledge regarding prevention of childhood obesity among mothers of children (0-12 yeas) in Kirumampakkam Village. 30 mothers were selected for the study by using convenient sample technique. According to the first objective few mothers had adequate knowledge regarding the prevention of childhood obesity and as per the second objective there was a significant association between the knowledge of the mother and demographic variables like family income number of children and educational qualification of the mother at the $\mathrm{P}<0.5$ level. 
Limitations

The sample selection was limited to Kirumampakkam Village

The data collection period of the study was one week

Sample size was 30 mothers

\section{Conclusion}

The study concluded that majority of the mothers had inadequate knowledge and moderately adequate knowledge. This shows that knowledge regarding childhood obesity was inadequate. There is a need to improve the knowledge regarding prevention of childhood obesity.

\section{References}

1. Qazi Iqbal Ahmad, Charoo Bashir Ahmad, and Sheikh Mushtaq Ahmad. Childhood Obesity, Indian Journal Endocrinol Metab, 2010 JanMar 14(1) 19-25.

2. Beeqaue M.D. et.al., Coronary risk incidence of obese children, Pp. 605612.

3. Chew C. et al., childhood obesity, causes and management. Journal of Paediatrics pp. 676-86.

4. Ditz W.H.et., al Obesity and television viewing children Pp. 807-812.
5. Dorth, R. Marlow Text book of Paediatric nursing $6^{\text {th }}$ edition, New Delhi, elsvier publication. 2002 pp. 670-672.

6. Graves $\mathrm{T}$ et. al An evaluation of parental problem solving training in the behavior treatment of childhood obesity. Journal of consulting and clinical psychology 1998 pp. 246250.

7. Marilyn J Khockenberry. Wong's essentials of pediatric nursing $7^{\text {th }}$ edition, New Delhi Jaypeee brothers pp. 433-438.

8. Ninganagouda G Patil. Impact of television viewing on childhood obesity, Nightingale Nursing times pp. 9-11.

9. Sobol A.M. Increasing Pediatric Obesity in United States. American Journal of diseases of children pp. 535-540.

10. Suraj Gupta the Short Text book of pediatrics. $9^{\text {th }}$ edition. New Delhi, Medical Publishers pp. 830-835.

11. Wolf M.C. school based intervention for obesity current approaches and future prospectus pp. 187-200. 